\title{
Synthesis, characterization and biological evaluation of some novel N- Mannich bases of heterocyclic 1,3,4-thiadiazole.
}

\author{
Sharma Piush ${ }^{* 1}$, Singh Charanjeet ${ }^{2}$ \\ ${ }^{1}$ Maharishi Arvind College of Pharmacy, Jaipur, Rajasthan (INDIA) \\ 2 Biyani Institute of Pharmaceutical Sciences, Jaipur, Rajasthan (INDIA)
}

\begin{abstract}
A series of some novel N-Mannich bases of heterocyclic 1,3,4-thiadiazole were synthesized through the condensation reaction of 1,3,4thiadiazole containing a aromatic secondary amine, aromatic aldehydes and cyclic compounds employing Mannich reaction and using conventional synthesis. All the synthesized compounds were obtained in the range of 57.41-83.3 \% yield. The structures of synthesized compounds were confirmed by UV, IR, ${ }^{1} \mathrm{H}$ NMR spectroscopy. the essential structural features responsible for interaction with receptor site are established within a suggested pharmacophore. The in vitro antibacterial activity of the synthesized compounds was determined, against two Gram-positive bacteria, viz. S. aureus \& B. subtilis and Gram-negative, viz. E. coli and K. pneumoniae, by cup-plate method using the standard drug ciprofloxacin. Minimum inhibitory concentrations (MIC) changed in the range of 1.56__ 200 mg mL_1. Compound 3b exhibited excellent activity against both bacteria. The in vitro antifungal activity of the synthesized compound was also evaluated by cup-plate method against the fungi A. niger and C. albicans compared with the standard drug Fluconazole. Compound 4a, 8a exhibited excellent activity against both fungi. The result has shown that the compounds are quite active against pathogens under study and were nontoxic. The anti-inflammatory activity of the compound was evaluated, on albino rats, by carageenan induced rat paw oedema method using the standard drug diclofenac so dium. Compound $7 \mathrm{~b}$ and $8 \mathrm{c}$ exhibited excellent anti-inflammatory and analgesic pharmacological activities. Structurally the compound $7 \mathrm{~b}$ has a greater number of unsaturated hydrocarbons in schiff base, which shows good lipophilic properties within electron rich morpholine ring in Mannich base. Statistical significance of differences between group was determined by one-way analysis of variance (ANOVA). Among the synthesized compounds $3 a, 4 b, 5 c, 7 b, 8 a$ and $8 c$ were found be the most active. All the synthesized compounds were found to be low lethal as ascertained by $\mathrm{LD}_{50}$ test.
\end{abstract}

Keywords: N- Mannich bases of heterocyclic 1,3,4-thiadiazole derivatives; Mannich reaction; antimicrobial agents; anti-inflammatory activity;

Article Info: Received 03 July 2019; Review Completed 20 August 2019; $\quad$ Accepted 23 August 2019; Available online 30 Aug 2019

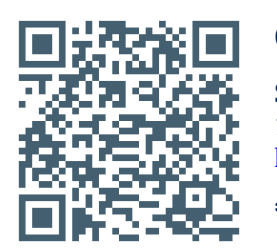

Cite this article as:

Sharma P, Singh C, Synthesis, characterization and biological evaluation of some novel N-Mannich bases of heterocyclic 1,3,4-thiadiazole., Journal of Drug Delivery and Therapeutics. 2019; 9(4-A):220-228

http://dx.doi.org/10.22270/jddt.v9i4-A.3332

Dr. Piush Sharma, Professor \& Principal, Maharishi Arvind College of Pharmacy, Jaipur, Rajasthan (INDIA)

\section{Introduction}

A lot of research has been done on N-Mannich bases derivatives and more research is going on in present time. From the literature it was concluded that the derivatives of N-Mannich bases of 1,3,4-thiadiazole shown diver type of activities viz antimicrobial, anti-inflammatory activities. Furthermore N-Mannich bases of 1,3,4-thiadiazole which contain an azomethine group attract much interest due to their synthetic along with antitumor (Dhapalapur MG et al.,1968) antimycobacterial (Patole J et al., 2006) antihypertensive (Turner S et al., 1988, Turner S et al., 1988), properties. The thiadiazole nucleus with N-C-S linkage exhibits a large number of biological activities (Kurtzer $\mathrm{F}$ et al., 1965). The treatment of microbial infections, especially bacterial infection, has become an important problem to solve due to the emergence of mulidrug resistance. As a contribution to the new antibacterial drug development we have previously synthesized N-Mannich bases of 1,3,4-thiadiazole derivatives. The aim of this study was to synthesize some NMannich bases having inhibition against microbial infections. An additionally anti-inflammatory activity was evaluated.

The interesting properties of many of these heteroccycles have increased the need for rapid synthesis of new, potentially useful sulfur-nitrogen containing heterocycles.

\section{Chemistry}

A lone pair of electrone is present on nitrogen atom. 1,3,4thiadiazole is a weak base. Electrone density on the nitrogen atom and facilitative reaction undergoes with eletrophilic 
reagents. It has a common structure, ie Ar- $\mathrm{C}_{2} \mathrm{~N}_{2} \mathrm{~S}-\mathrm{NHCNHN}=\mathrm{CH}-\mathrm{Ar}_{\mathrm{r}}$ which may consist of an aromatic secondary amine of 1,3,4-thiadiazole ring, a thionyl carbon (none of the valencies of which is satisfied by hydrogen) asa thiosemicarbazide and Schiff base between the flat carbon $(-\mathrm{N}=\mathrm{CH}-)$. From the considerations of the above facts, it was planned to synthesize Mannich bases of 1-substituted-4-(4-(phenylamino)phenyl)-1,3,4-thiadiazole2 -yl)thiosemicarbazide by carrying out reaction between 1 substituted-4-(5-(4-(phenylamino)phenyl)-1,3,4-thio diazole-2-yl)thiosemicarbazide,formaldehyde and dimethyl amine, morpholin, piperidine.

Basic moiety 4-(5-(4-(phenylamino) phenyl)-1,3,4-thio diazol-2-yl)thiosemicarbazide (1) was synthesized from 5-(4-(phenylamino)phenyl)-1,3,4-thiodiazole-2-amine, into their corresponding carbon disulphide in presence of alcoholic $\mathrm{NaOH}_{\mathrm{a}} \mathrm{TO}$ obtain the sodium salts, followed by the addition of the hydrazine hydrate gives the thiosemicarbazide compound, which involved the reported reaction mechanism of Nucleophilic Addition Reaction (Ananthanaryan R et al., 2005). Further derivatives of methylene-4-(5-(-(phenylamino) phenyl-1,3,4-thiadiazol-2yl)thiosemicarbazide 2(a-f), were synthesized by 4-(-5-(4-(phenylamino)phenyl-1,3,4-thiadiazol-2-

yl)thiosemicarbazide and different aromatic and heterocycle aldehydes. Reaction mechanism of this step undergoes Nucleophilic Addition Reaction (Morrison R T rt al., 2005). Title compounds 3(a-c), 4(a-c), 5(a-c), 6(a-c), $\mathbf{7 ( a - c ) , ~ 8 ( a - c ) ~ d e r i v a t i v e s ~ o f ~ N - M a n n i c h ~ b a s e s ~ o f ~ h e t e r o c y c l i c ~}$ 1,3,4-thiadiazol were prepared from 1-R 1 Substituted-4-(5(4-(phenylamino)phenyl)-1,3,4)thiosemicarbazide and formaldehyde, dimethylamine, morpholine, piperidine. Reaction mechanism of this step undergoes N-Mannich Base Reaction (Agarwal O P, 2006). Mannich reaction is an approach to bring about condensation between a compound containing atleast one active hydrogen ayom , formaldehyde and ammonia or a primary amine or a econdary amine. An example of Mnnich reaction is reaction between acetophenone or another aryl amino [(diphenyl amine) compound containing active hydrogen], formaldehyde and secondary amine (Adam R., 1996).

\section{MATERIALS AND METHODS}

Preparation of 4-(5-(4-(phenylamino)phenyl)-1,3,4thiadiazol-2-yl)thiosemicarbazide (1)

$3.76 \mathrm{~g}(0.014 \mathrm{~mol}) \quad 5$-(4-(phenylamino) phenyl)-1,3,4-thia diazol-2-amine was taken in $15 \mathrm{ml}$ of dimethylformamide (DMF) in a flat bottom flask. To this sodium hydroxide (0.014mol), carbon disulphide $(0.014 \mathrm{~mol})$ were added. The mixture was stirred at $15-20^{\circ} \mathrm{C}$ for $1 \mathrm{~h}$, to the stirred mixture was added hydrazine hydrate $(0.014 \mathrm{~mol})$ and stirred continue for $1 \mathrm{~h}$ more at $60^{\circ} \mathrm{C}$. On adding water, a paleyellow solid separated out which was recrystallized from DMF-Ethanol. The pale yellow coloured product obtained, yield $78 \%$, melting point $251^{\circ} \mathrm{C}$ and calculated $\mathrm{R}^{\mathrm{f}} 0.72$ (Pandeya S N, et al., 1999).

Derivatives of methylene- 4-(5-(4-(phenylamino) phenyl)-1,3,4-thiadiazol-2-yl)thiosemicarbazide 2(a-f)

In a dry flat bottom flask 3.42g 4-(5-(4-(phenylamino) phenyl)-1,3,4-thiadiazole-2-yl)thiosemicarbazide was taken in $35 \mathrm{ml}$ of ethanol. This solution was added an equimolar quantity of the appropriate different aromatic and heterocyclic aldehydes in a small quqntity of alcohol. Then added a few drops of glacial acetic acid, stirring was done for 5 min. Immediate precipitation occurred and solid was filtered, dried and recrystellized from hot ethanol. The white powder product obtained, yield $73 \%$, melting point $243^{\circ} \mathrm{C}$ andclculated $\mathrm{R}^{\mathrm{f}} 0.68$ (Yogeeswari Pet al.,2004).

Synthesis of $\mathrm{N}$-Maanich bases of heterocyclic 1,3,4thiadiazol derivatives, 3(a-c), 4(a-c), 5(a-c), 6(a-c), 7(ac), 8(a-c) (Pandeya $S$ N et al.,1999).

Preparation of 4-(5-(4-(N-(substituted) methyl)-Nphenyl amino) phenyl)- 1,3,4-thiadiazol- 2-yl)-1benzylidene thiosemicarbazide(3a-c)

2.44g (0.005mol) 1-benezylidene-4-(5-(4-(phenylamino) phenyl)-1,3,4-thiadiazol-2-yl)thiosemicarbazide was placed in a $250 \mathrm{ml}$ round bottom flask in $8 \mathrm{ml}$ tetrahydronfuran. To this solution was added $2 \mathrm{ml}$ formaldehyde and 2-3 drops of concentrated hydrochloric acid. To this mixture $(0.005 \mathrm{~mol})$ dimethylamine, morpholine and piperidine(a-c) were added with cooling and shaking respectively. The reaction mixture was allowed to stand at room temperature for $1 \mathrm{hr}$ with occasional shaking, after which it was warmed on a steam bath for $15 \mathrm{~min}$. At the end of the period, the contents were cooled and the product obtained was recrystallized with choloroform: petroleum ether (50:50). Synthesized compounds (3a-c)were obtained with yield $64.2 \%, 72.7 \%$ and $68.4 \%$ respectively. The colored product observed, melting point $241^{\circ} \mathrm{C}$ and calculated $\mathrm{R}^{\mathrm{f}} 0.74$.

Preparation of 1-(o-hydroxybenzylidene)-4-(5-(4-(N(substituted)-N-phenylamino)phenyl)-1,3,4-thiadiazol2-yl)thiosemecarbazide(4a-c)

2.23g (0.005mol) 1-(o-htdroxybenzylidene)-4(5-(4-(phenyl amino) phenyl)-1,3,4-thiadiazol-2-yl) thiosemecarbazide was placed in a $250 \mathrm{ml}$ round bottom flask in $8 \mathrm{ml}$ tetrahydrofuran. To this solution was added $2 \mathrm{ml}$ formaldehyde and 2-3 drops of concentrated hydrochloric acid. To this mixture $(0.005 \mathrm{~mol})$ dimethylamine, morpholine and piperidine (a-c) were added with cooling and shaking respectively. The reaction mixture was allowed to stand at room temperature for $1 \mathrm{hr}$ with occasional shaking, after which it was warmed on a steam bath for $15 \mathrm{~min}$. At the end of the period, the contents were cooled and the product obtained was recrystallized with chloroform : petroleum (50:50). Synthesized compounds(4a-c)were obtained with yield $57.41 \%, 66.7 \%$ and63.6\%respectively. The colourless product observed, melting point $230^{\circ} \mathrm{C}$ and calculated $\mathrm{R}^{\mathrm{f}}$ 0.54 .

Preparation of 1-(4-chlorobenzylidene)-4-(5-(4-(N(substituted) methyl)-N-phenylamino)phenyl)-1,3,4thia diazol-2-yl) thiosemecarbazide(5a-c) thiadiazol-2yl) thiosemecarbazide(5a-c)

2.32g (0.005mol) 1-(4-chlorobenzylidene)-4-(5-(4-(phenyl amino) phenyl)-1,3,4-thiadiazol-2-yl)thiosemecarbazide was placed in $250 \mathrm{ml}$ round bottom flask in $8 \mathrm{ml}$ tetrahydrofuran. To this solution was added $2 \mathrm{ml}$ formaldehyde and 2-3 drops of concentrated hydrochloric acid. To this $(0.005 \mathrm{~mol})$ dimethylamine, morpholine and piperidine (a-c) were added with cooling and shaking respsctively. The reaction mixture was allowed to stand at room tempersture for $1 \mathrm{hr}$ with occasional shaking, after which it was warmed on the steam bath for $15 \mathrm{~min}$. At the end of the period, the contents were cooled and the product obtained was recrystallized with chloroform: petroleum (50:50). Synthesized compounds 95A-C0were obtained with yield $58 \%, 65.4 \%$ and $61.6 \%$ respectively. The colourless product observed, melting point $240^{\circ} \mathrm{C}$ and calculated $\mathrm{R}^{\mathrm{f}} 0.46$. 
Preparation of 1-(4-(dimethylamino) benzylidene)-4-(5(4-(N-substituted)methyl)-N-phenylamino) phenyl)1,3,4-thiadiazol-2-yl)thiosemicarbazide(6a-c)

$2.37 \mathrm{~g} 0.005 \mathrm{~mol} 1-(4-($ dimethylamino) benzylidene)-4-(5-(4(phenylamino) phenyl)-1,3,4-thiadiazol-2-yl) thiosemi carbazide was placed in $250 \mathrm{ml}$ round bottm flask in $8 \mathrm{ml}$ tetrahyrofurane. To this solution was added $2 \mathrm{ml}$ formaldehyde and 2-3 drops of concentrated hydrochloric acid. To this $(0.005 \mathrm{~mol})$ dimethylamine, morpholine and piperidine (a-c) were added with cooling and shaking respectively. The reaction mixture was allowed to stand at room temperature for $1 \mathrm{hr}$ with occasional shaking, after whicw it was warmed on a steam bath for $15 \mathrm{~min}$. At the end of the period, the contents were cooled and the product obtained was recrystallized with chloroform: petroleum (50:50). Synthesised compounds (6a-c)were found with yield $69.8 \%, 73.7 \%$ and $70 \%$ respectivele. $\mathrm{T}$ he white crystalline product observed, melting point $243^{\circ} \mathrm{C}$ and calculated $\mathrm{R}^{\mathrm{f}} 0.63$.

Preparation of 4-(-5-(4-(N-(substituted)methyl)-Nphenylamino)phenyl)-1,3,4-thiadiazol-2-yl)-1-(3phenylallylidene)thiosemicarbazide (7a-c)

$2.28 \mathrm{~g} \quad(0.005 \mathrm{~mol}) \quad 1$-(3-phenylallylidene)-4-(5-(4-(phenyl amino)phenyl)-1,3,4-thiadiazol-2-yl)thiosemicarbazide was placed in a round bottom flask in $8 \mathrm{ml}$ tetrahydrofuran. To this solution was added $2 \mathrm{ml}$ formaldehyde and 2-3 drops of concentrared hydrochloric acid. Tot this $(0.005 \mathrm{~mol})$ dimethylamine, morpholie and piperiden (a-c) were added with cooling and shaking respectively. The reaction mixture was allowed to stand at room temperature for $1 \mathrm{hr}$ with occasional shaking, after which it was warmed on steam bath for $15 \mathrm{~min}$. At the end of the period, the contents were cooled and the product obtained was recrystallized with chloroform: petroleum (50:50). Synthesised compounds (7ac) were obtained with yield $75 \%, 76.8 \%$ and $74 \%$ respectively. The pale yellow product observed, melting point $227^{\circ} \mathrm{C}$ and calculated $\mathrm{R}^{\mathrm{f}} 0.71$.

Preparation of 4-(5-(4-(N-(substituted) methyl-N-phenyl amino) phenyl)-1,3,4-thiadiazol-2-yl)-1-(furan-2-yl) methylene) thiosemicarbazide (8a-c)

2.10g (0.005mol) 1-(furan-2-yl)methylene)-4-(5-(4-(phenyl amino)phenyl)-1,3,4-thiadiazol-2-yl)thiosemicarbazide was placed in round bottom flask in $8 \mathrm{ml}$ tetrahydrofuran. TOthis solution was added $2 \mathrm{ml}$ formaldehyde and 2-3 drops of concentrated hydrochloric acid. To this $(0.005 \mathrm{~mol})$ dimethylamine, morpholine and piperidine (a-c)were added with cooling and shaking respectively. The reaction mixture was allowed to stand at room temperature for $1 \mathrm{hr}$ with occasional shaking, after which it was warmed on a steam bath for $15 \mathrm{~min}$. At the end of the period, the contents were cooled and the product obtained was recrystallized with chloroform : petroleum (50:50). Synthesised compounds (8a-c) were obtained with yield $78.8 \%, 83.3 \%$ and $79.6 \%$ respectively. The colouless product observed, melting point $249^{\circ} \mathrm{C}$ and calculated $\mathrm{R}^{\mathrm{f}} 0.59$.

Fig. 1 Graphical abstract of synthesized title compounds.<smiles>Nc1nnc(-c2ccc(Nc3ccccc3)cc2)s1</smiles>

5-[4-(pherylam ino)pheny]-1,3,4-thi adiazol-2-amine<smiles>NNC(=S)Nc1nnc(-c2ccc(Nc3ccccc3)cc2)s1</smiles>

4-\{5-[4-(phen ylamino) phenyl]-1,3,4-thiadiazol-2-yl\} thiosemicarbazide<smiles>[R8]C=C=NNC(=S)Nc1nnc(-c2ccc(Nc3ccccc3)cc2)s1</smiles>

1-R Substituted-4-(5-(4-(phenylamin0)-1,3,4-thiadiazol-2-yl)thiosemicarbazide

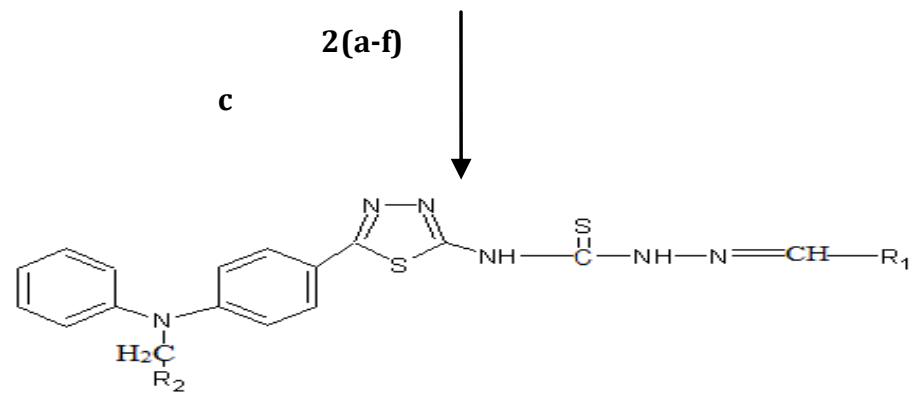


4-(5-(4-(N-phenyl-N-(R2-substituted)methylamino)phenyl)-1,3,4-thiadiazol-2-yl)-1-R1-substituted-thiosemicarbazide, 3(a-c), 4(a-c), 5(a-c), 6(a-c), 7(a-c), 8(a-c).

\begin{tabular}{|c|c|c|c|c|}
\hline \multirow[t]{2}{*}{ COMPOUND } & \multirow[t]{2}{*}{$\boldsymbol{R}_{1}$} & \multicolumn{2}{|l|}{$R_{2}$} & \\
\hline & & $\mathbf{a}$ & b & C \\
\hline 3 & $\mathrm{C}_{6} \mathrm{H}_{5}$ & $\mathrm{~N}\left(\mathrm{CH}_{3}\right)_{2}$ & & \\
\hline 4 & $\mathrm{o}-\mathrm{C}_{6} \mathrm{H}_{4}-\mathrm{OH}$ & $\mathrm{N}\left(\mathrm{CH}_{3}\right)_{2}$ & & \\
\hline 5 & $\mathrm{p}-\mathrm{C}_{6} \mathrm{H}_{4}-\mathrm{Cl}$ & $\mathrm{N}\left(\mathrm{CH}_{3}\right)_{2}$ & & \\
\hline 6 & $\mathrm{p}-\mathrm{C}_{6} \mathrm{H}_{4}-\mathrm{N}\left(\mathrm{CH}_{3}\right)_{2}$ & $\mathrm{~N}\left(\mathrm{CH}_{3}\right)_{2}$ & & \\
\hline 7 & $\mathrm{CH}=\mathrm{CH}-\mathrm{C}_{6} \mathrm{H}_{5}$ & $\mathrm{~N}\left(\mathrm{CH}_{3}\right)_{2}$ & & \\
\hline 8 & $\mathrm{C}_{4} \mathrm{H}_{3} \mathrm{O}^{*}$ & $\mathrm{~N}\left(\mathrm{CH}_{3}\right)_{2}$ & & \\
\hline
\end{tabular}

*Furan (a) $\mathrm{NaOH}, \mathrm{DMF}, \mathrm{CS} 2, \mathrm{NH}_{2} \mathrm{NH}_{2} \cdot \mathrm{H}_{2} \mathrm{O}, 60^{\circ} \mathrm{C}$. (b) Aromatic aldehydes, Few drops $\mathrm{CH}_{3} \mathrm{COOH}, \mathrm{C}_{2} \mathrm{H}_{5} \mathrm{OH}$. (c) Tetrahydrofuran, Formaldehyde, concentrated hydrochloric acid, Dimethylamine, Morpholine and Piperidine (a-c), Room temperature for $1 \mathrm{hr}$.

\section{Characterization of the synthesized compounds}

Synthesised compounds N-Mannich bases of heterocyclic 1,3,4-thiadiazol derivatives $\mathbf{3}(\mathbf{a}-\mathbf{c}), \mathbf{4}(\mathbf{a}-\mathbf{c}), \mathbf{5}(\mathbf{a}-\mathbf{c}), \mathbf{6}(\mathbf{a}-\mathbf{c})$, $\mathbf{7}(\mathbf{a}-\mathbf{c}), \mathbf{8}(\mathbf{a}-\mathbf{c})$ were synthesized by the reaction between 1 R1Substituted-4-(5-(4-(phenylamino) phenyl)-1,3,4-

thiadiazol-2-yl)thiosemicarbazide and formaldehyde, dimethylamine, morpholine, piperidine using reported method. All melting points (m.p) were determined in open capillary method using Jindal point apparatus and were uncorrected.The purity of the compounds was routinely checked by thin layer chromatography (TLC) using silica gel G (Merck). The instruments used for spectroscopy data are
FTIR : Bruker tensor-27 spectrophotometer (ATR) with diffuse reflectance method. H1NMR :JEOL GSX-400, $60 \mathrm{MHz}$ spectrometer in $\mathrm{CDCl}_{3}$, TMS (tetra methyl silane) as an internal standard. $\mathrm{H}^{1} \mathrm{NMR}$ and IR spectra were consistent with the assigned structure. The results obtain which are shown in table 1 indicates, derivatives of $\mathrm{N}$-Mannich bases of heterocyclic 1,3,4-thiadiazol 3(a-c), 4(a-c), 5(a-c), 6(a-c), $\mathbf{7}(\mathbf{a}-\mathbf{c}), \mathbf{8 ( a - c )}$ were synthesized under conventional method under reaction suitable conditions. All compounds were conformed to the structures envisaged. Thermodynamics properties, physic-chemical properties and costant are given table 2and 3D structure of syhthesised title compounds are shown fig 2.

Table 1 Characterization of synthesized compounds.

\begin{tabular}{|c|c|}
\hline $\begin{array}{l}\text { Compound } \\
\text { name }\end{array}$ & Specroscopic data \\
\hline $3(a-c)$ & 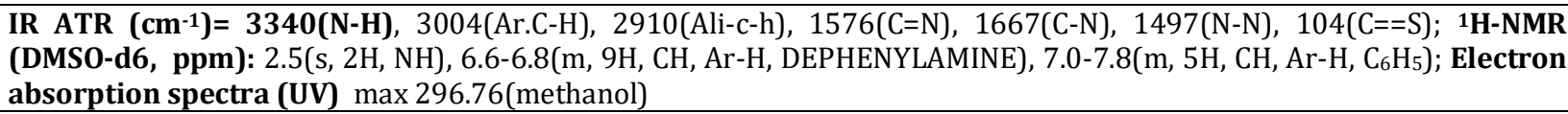 \\
\hline $4(a-c)$ & 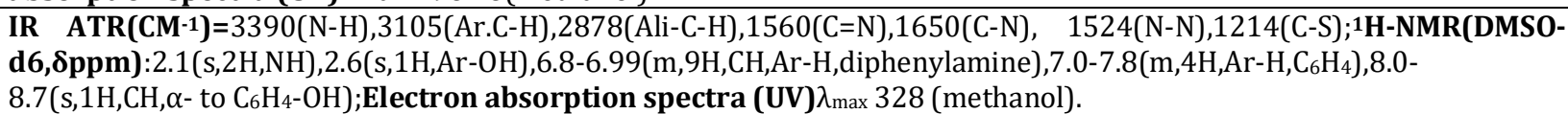 \\
\hline $5(a-c)$ & $\begin{array}{l}\text { IRATR(CM-1)=3420(N-H),3020(Ar-C-H),2915(Ali-C-H),1720(C=N),1570(C-N),1645(Ar-C=C),1440(N-N),1210(C-S),1095 } \\
\left.\text { (Ar.C-Cl); }{ }^{1} \text { H-NMR(DMSO-d6, } \mathbf{8 p p m}\right): 2.5(\mathrm{~s}, 2 \mathrm{H}, \mathrm{NH}), 2.5-2.8\left(\mathrm{t}, 3 \mathrm{H}, \mathrm{N}\left(\mathrm{CH}_{3}\right) 2\right), 6.6-6.8(\mathrm{~m}, 9 \mathrm{H}, \mathrm{CH}, \mathrm{Ar}-\mathrm{H} \text {,diphenylamine);Electron } \\
\text { absorption spectra (UV) } \lambda_{\max } 334.6(\text { methanol). }\end{array}$ \\
\hline $6(a-c)$ & 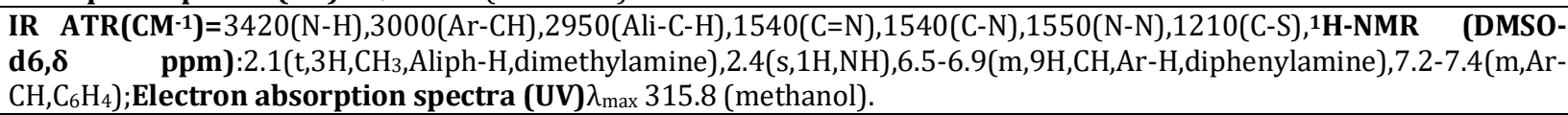 \\
\hline $7(a-c)$ & 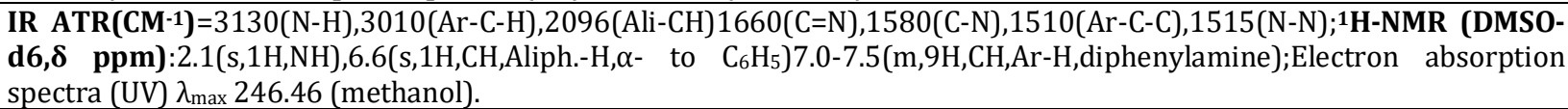 \\
\hline $8(a-c)$ & 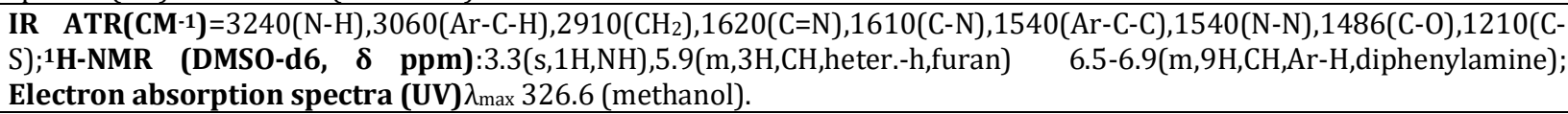 \\
\hline
\end{tabular}


<smiles>[R]C=NNC(=S)Nc1nnc(-c2ccc(N(C[R2])c3ccccc3)cc2)s1</smiles>

$\mathrm{R}_{2}$-substituted compunds (N-Mannich bases compounds)

Table 2 physiochemical properties of synthesized compounds.

\begin{tabular}{|c|c|c|c|c|c|c|c|c|c|}
\hline Comp. & M.formula & M.wt & $\begin{array}{l}\text { Rast's } \\
\text { M.wt. }\end{array}$ & $\begin{array}{l}\text { Depression } \\
\text { of } \\
\text { m.p. } \Delta T\left({ }^{\circ} \mathrm{C}\right)\end{array}$ & B.P.[K] & $\begin{array}{l}\text { Log } \\
P\end{array}$ & $\mathrm{MR}\left[\mathrm{CM}^{3} / \mathrm{mol}^{2}\right]$ & $\begin{array}{l}\text { HENRY'S } \\
\text { LAW }\end{array}$ & $\begin{array}{l}\text { Gibbs } \\
\text { Energy[kJ/mol] }\end{array}$ \\
\hline $3 a$ & $\mathrm{C}_{25} \mathrm{H}_{25} \mathrm{~N}_{7} \mathrm{~S}_{2}$ & 488 & 484.9 & 81.87 & 1342.73 & 7.39 & 147.48 & 6.31 & 298.15 \\
\hline $3 \mathbf{b}$ & $\mathrm{C}_{27} \mathrm{H}_{27} \mathrm{~N}_{7} \mathrm{OS}_{2}$ & 530 & 532.5 & 74.55 & 1435.39 & 6.99 & 156.53 & 6.31 & 298.15 \\
\hline $3 c$ & $\mathrm{C}_{28} \mathrm{H}_{29} \mathrm{~N}_{7} \mathrm{~S}_{2}$ & 528 & 529.3 & 75.00 & 1431.32 & 8.12 & 159.4 & 6.31 & 298.15 \\
\hline $4 \mathbf{a}$ & $\mathrm{C}_{25} \mathrm{H}_{25} \mathrm{~N}_{7} \mathrm{OS}_{2}$ & 504 & 506.4 & 78.39 & 1423.35 & 7 & 149.29 & 6.31 & 298.15 \\
\hline $4 \mathrm{~b}$ & $\mathrm{C}_{27} \mathrm{H}_{27} \mathrm{~N}_{7} \mathrm{O}_{2} \mathrm{~S}_{2}$ & 546 & 544.3 & 72.94 & 1516.01 & 6.6 & 158.34 & 6.31 & 298.15 \\
\hline $4 \mathrm{c}$ & $\mathrm{C}_{28} \mathrm{H}_{29} \mathrm{~N}_{7} \mathrm{OS}_{2}$ & 544 & 546.8 & 72.63 & 1511.94 & 7.73 & 161.21 & 6.31 & 298.15 \\
\hline $5 a$ & $\mathrm{C}_{25} \mathrm{H}_{24} \mathrm{ClN}_{7} \mathrm{~S}_{2}$ & 521.5 & 524.5 & 75.54 & 1385.14 & 7.95 & 152.08 & 6.31 & 298.15 \\
\hline $5 \mathbf{b}$ & $\mathrm{C}_{27} \mathrm{H}_{26} \mathrm{ClN}_{7} \mathrm{OS}_{2}$ & 563.5 & 565.3 & 70.10 & 1477.8 & 7.55 & 161.13 & 6.31 & 298.15 \\
\hline $5 c$ & $\mathrm{CH}_{28} \mathrm{H}_{28} \mathrm{ClN}_{7} \mathrm{~S}_{2}$ & 561.5 & 558.2 & 71.50 & 1473.73 & 8.68 & 164.01 & 6.31 & 298.15 \\
\hline $6 a$ & $\mathrm{C}_{27} \mathrm{H}_{30} \mathrm{~N}_{8} \mathrm{~S}_{2}$ & 531 & 533.5 & 74.42 & 1405.91 & 7.67 & 162.66 & 6.31 & 298.15 \\
\hline $6 \mathbf{b}$ & $\mathrm{C}_{29} \mathrm{H}_{32} \mathrm{~N}_{8} \mathrm{OS}_{2}$ & 573 & 570.1 & 69.63 & 1498.57 & 7.27 & 171.71 & 6.31 & 298.15 \\
\hline 6c & $\mathrm{C}_{30} \mathrm{H}_{34} \mathrm{~N}_{8} \mathrm{~S}_{2}$ & 571 & 573.4 & 69.24 & 1494.5 & 8.41 & 174.58 & 6.31 & 298.15 \\
\hline $7 a$ & $\mathrm{C}_{27} \mathrm{H}_{27} \mathrm{~N}_{7} \mathrm{~S}_{2}$ & 514 & 513.5 & 77.31 & 1392.65 & 7.27 & 157.53 & 6.31 & 298.15 \\
\hline $7 \mathbf{b}$ & $\mathrm{C}_{29} \mathrm{H}_{29} \mathrm{~N}_{7} \mathrm{OS}_{2}$ & 556 & 558.6 & 71.07 & 1485.31 & 6.87 & 166.58 & 6.31 & 298.15 \\
\hline $7 c$ & $\mathrm{C}_{30} \mathrm{H}_{31} \mathrm{~N}_{7} \mathrm{~S}_{2}$ & 554 & 556.2 & 71.38 & 1481.24 & 8.01 & 169.58 & 6.31 & 298.15 \\
\hline $8 a$ & $\mathrm{C}_{23} \mathrm{H}_{23} \mathrm{~N}_{7} \mathrm{OS}_{2}$ & 478 & 475.8 & 83.43 & 1320.49 & 6 & 140 & 6.31 & 298.15 \\
\hline $8 b$ & $\mathrm{C}_{25} \mathrm{H}_{25} \mathrm{~N}_{7} \mathrm{O}_{2} \mathrm{~S}_{2}$ & 520 & 518.1 & 76.62 & 1413.15 & 5.6 & 149.05 & 6.31 & 298.15 \\
\hline $8 c$ & $\mathrm{C}_{26} \mathrm{H}_{27} \mathrm{~N}_{7} \mathrm{OS}_{2}$ & 518 & 521.1 & 76.19 & 1409.08 & 6.74 & 151.92 & 6.31 & 298.15 \\
\hline
\end{tabular}

Fig. 2 Three dimension structure of title compound with energy minima.

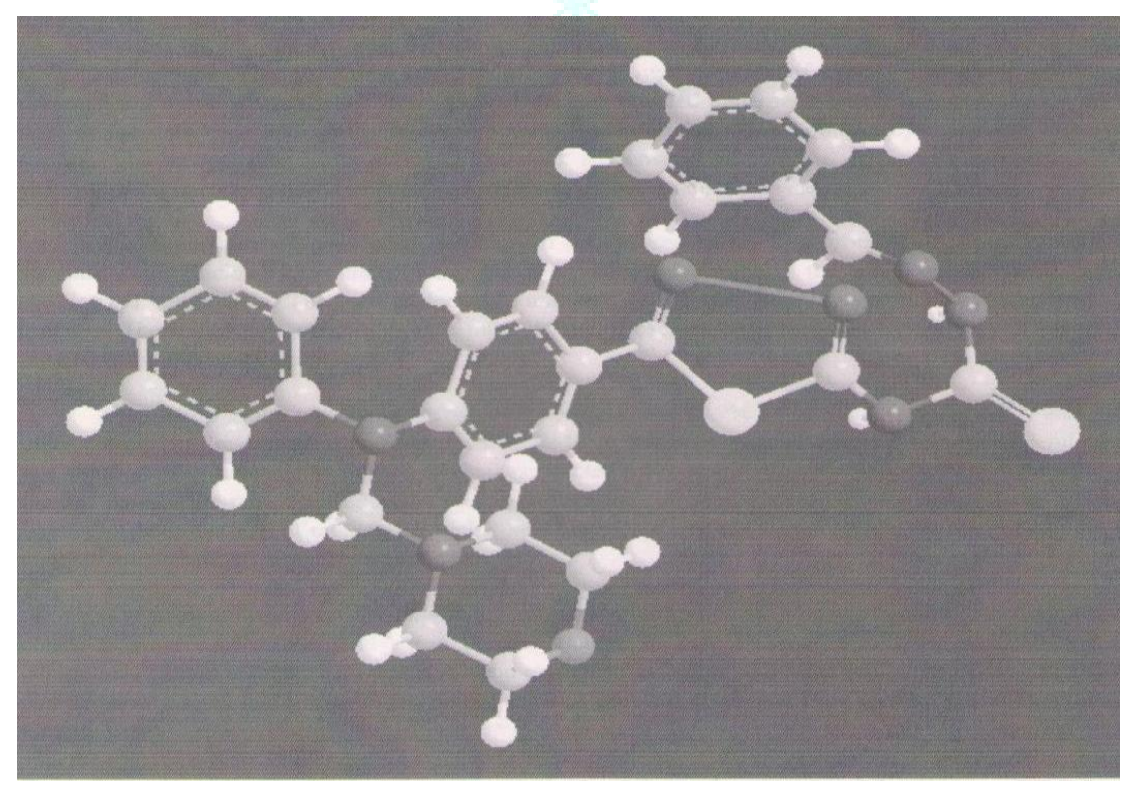

\section{Biological Evaluation}

1. Antimicrobial Activity (Pelczar J. M. et al., 2003 and Ananthanaryan R et al., 2005).

In an approach to develop and synthesised new antimicrobial and anti-inflammatory agents,derivatives of $\mathrm{N}$ Mannich bases of heterocyclic 1,3,4-thiadiazole 3(a-c),4(ac),5(a-c),6(a-c),7(a-c),8(a-c).
The in vitro antimicrobial activity of the synthesized compounds was screened by cup plate method against two gram positive bacteria viz. Staphylococcus aureus\& Bacillus subtilis and two gram negative bacteria viz. Escherichia coli, Klebsiella pneumoniae and two pathogenic fungi Candida albicans, Aspergillus niger. The standard antibacterial agent used in the study was Ciprofloxacin, for the antifungal standard drug fluconazole. Twenty five milliliter of molten nutrient agar [ Sabouraud's Dextrose CODEN (USA): JDDTAO 
Agar (at pH 6.8)] was poured into pre sterilized Petri-dishes and allowed to solidify at room temperature. Broth cultures of the test microbial were used as inoculums under sterile conditions. Dimethyl formamide (DMF) was used as control and as solvent to prepare the stock solutions of the synthesized compounds. The concentration of the prepared stock solutions was $100 \mu \mathrm{g} / \mathrm{ml}$. Then $250 \mu \mathrm{l}$ of the stock solution was poured in to each cup, the Petri dishes were incubated at $25^{\circ} \mathrm{C} \pm 2^{\circ} \mathrm{C}$ for 48 hours and were examined for zone of inhibition (in $\mathrm{mm}$ ) and \% inhibition, exhibited by the test and standard compounds, which is given in Tables 3 $\& 4$.

\section{Anti-inflammatory Activity}

Carrageenin induced rat paw oedema model (Kulkarni S.K.,1999 and Winter C.A., et al., 1962)

The anti-inflammatory activity of the standard drug diclofenac sodium and synthesized compounds, 3a, 3c,4b, $\mathbf{5 c}, \mathbf{6 a}, \mathbf{6 c}, \mathbf{7 b}, \mathbf{8 a}$, and $\mathbf{8 c}$, was determined against carrageenan induced acute paw oedema in albino rats (66 numbers weighing 200-225 g). The $1 \% \mathrm{w} / \mathrm{v}$ solution of carrageenan for injection was prepared in normal saline $(0.9 \% \mathrm{NaCl})$ and $0.1 \mathrm{ml}$ was injected underneath planter region. The $50 \mathrm{mg} / \mathrm{kg}$ dose of standard drug and synthesized compounds was administered in animals, by oral route using oral feeding tube through tuberculim syringe. The stock suspensions of standard and synthesized compounds were prepared in concentration of $10 \mathrm{mg} / \mathrm{ml}$ of $2 \% \mathrm{w} / \mathrm{v}$ CMC in distilled water.
The albino rats were weighed and marked and housed as six in a group. One group was for the standard drug (diclofenac sodium), one group served as control and the other groups were for the synthesized compounds. The hind paws (right and left) of the rats were marked just beyond tibio-tarsal junction. The initial paw volume (both right and left) of each rat was recorded by mercury displacement method using Plethysmograph.

The control group was administered with normal saline $(0.9 \% \mathrm{w} / \mathrm{v} \mathrm{NaCl}) \quad(2.5 \mathrm{ml} / \mathrm{kg})$ orally and other groups with respective drug suspension in CMS as per body weight. After 30 minutes, $0.1 \mathrm{ml}$ of $1 \% \mathrm{w} / \mathrm{v}$ solution of carrageenan in normal saline was injected using No. 26 gauge needle, in the planter region of the left paw of the rats. The right paw served as reference non-inflammed paw for comparison. The paw volume of both the legs of rats treated with control, standard and test compounds were recorded at 30,60, and 120 minutes after carrageenan challenge.

The percent difference in the right and left paw volumes of each animal of control, standard and test compounds were calculated and meen percent change in paw volume in control, standard and test compounds treated animals were compared and expressed as percent ooedema inhibition of drug in Table 5 and percent oedema inhibition shown by the test and standard compounds are compared and expressed in Graph 3.

Table 3 Results of in vitroantimicrobial activity of synthesized compunds 3-8(a-c)

\begin{tabular}{|c|c|c|c|c|c|c|c|c|}
\hline \multirow[t]{3}{*}{ Comp. } & \multicolumn{4}{|c|}{ Gram +ve bacteria } & \multicolumn{4}{|c|}{ Gram -ve bacteria } \\
\hline & \multicolumn{2}{|c|}{ S. aureus } & \multicolumn{2}{|c|}{ B. subtilis } & \multicolumn{2}{|l|}{ E. coli } & \multicolumn{2}{|c|}{ K. Pneumoniae } \\
\hline & $\begin{array}{l}\mathrm{ZOI} \\
(\mathrm{mm})\end{array}$ & $\begin{array}{l}\% \\
\text { Inhibition }\end{array}$ & $\begin{array}{l}\mathrm{ZOI} \\
(\mathrm{mm})\end{array}$ & $\begin{array}{l}\% \\
\text { Inhibition }\end{array}$ & $\begin{array}{l}\mathrm{ZOI} \\
(\mathrm{mm})\end{array}$ & $\begin{array}{l}\% \\
\text { Inhibition }\end{array}$ & $\begin{array}{l}\mathrm{ZOI} \\
(\mathrm{mm})\end{array}$ & $\begin{array}{l}\% \\
\text { Inhibition }\end{array}$ \\
\hline $5 a$ & 12 & 52.17 & 18 & 85.71 & 10 & 43.47 & 16 & 69.56 \\
\hline $5 b$ & 19 & 82.60 & 20 & 95.23 & 08 & 34.78 & 15 & 65.21 \\
\hline 5c & 06 & 26.08 & 08 & 38.09 & 14 & 60.86 & 13 & 56.52 \\
\hline $6 a$ & 19 & 82.60 & 12 & 57.14 & 12 & 52.17 & 13 & 56.52 \\
\hline $6 b$ & 15 & 65.21 & 06 & 28.57 & 08 & 34.78 & 06 & 26.08 \\
\hline 6c & 04 & 17.39 & 14 & 66.66 & 06 & 26.08 & 14 & 60.86 \\
\hline $7 a$ & 04 & 17.39 & 12 & 57.14 & 06 & 26.08 & 14 & 60.86 \\
\hline $7 \mathbf{b}$ & 16 & 69.56 & 10 & 47.61 & 06 & 26.08 & 10 & 43.47 \\
\hline 7c & 06 & 26.08 & 06 & 28.57 & 08 & 34.78 & 12 & 52.17 \\
\hline $8 a$ & 09 & 39.13 & 08 & 38.09 & 08 & 34.78 & 10 & 43.47 \\
\hline $8 b$ & 12 & 52.17 & 08 & 38.09 & 12 & 52.17 & 06 & 26.08 \\
\hline $8 c$ & 05 & 21.73 & 12 & 57.14 & 08 & 34.78 & 09 & 39.13 \\
\hline $9 a$ & 05 & 21.73 & 06 & 28.57 & 12 & 52.17 & 15 & 65.21 \\
\hline $9 b$ & 03 & 13.04 & 08 & 38.09 & 08 & 34.78 & 15 & 65.21 \\
\hline 9c & 12 & 52.17 & 06 & 28.57 & 14 & 60.86 & 15 & 65.21 \\
\hline $10 a$ & 06 & 26.08 & 06 & 28.57 & 08 & 34.78 & 11 & 47.82 \\
\hline $10 \mathrm{~b}$ & 08 & 34.78 & 12 & 57.14 & 10 & 43.47 & 13 & 56.52 \\
\hline 10c & 06 & 26.08 & 06 & 28.57 & 16 & 69.56 & 09 & 39.13 \\
\hline $\begin{array}{l}\text { Standard } \\
\text { (ciprofloxacin) }\end{array}$ & 23 & 100.00 & 21 & 100.00 & 23 & 100.00 & 23 & 100.00 \\
\hline
\end{tabular}


Graph 1 Comparison of in vitro antibacterial activity exhibited by the test compounds 3-8(a-c) and standard drug ciprofloxacin

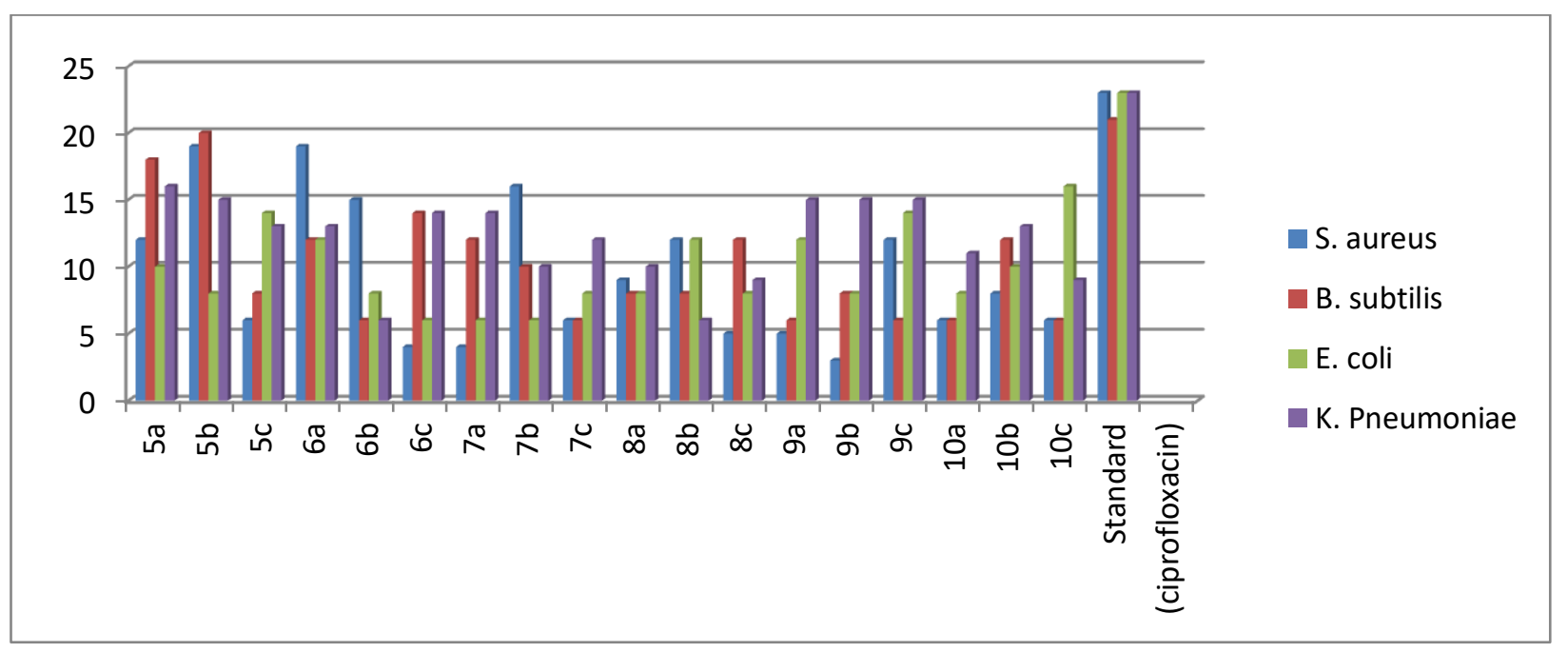

Table 4 Results of in vitro antifungal activity of synthesized compunds

\begin{tabular}{|c|c|c|c|c|}
\hline \multirow[t]{2}{*}{ Comp. } & \multicolumn{2}{|c|}{ A.niger } & \multicolumn{2}{|c|}{ C.albicans } \\
\hline & $\begin{array}{c}\text { Zone of } \\
\text { inhibition }(\mathrm{mm})\end{array}$ & \% inhibition & $\begin{array}{c}\text { Zone of } \\
\text { inhibition }(\mathrm{mm})\end{array}$ & $\%$ inhibition \\
\hline $3 a$ & 13 & 68.42 & 05 & 31.25 \\
\hline $3 \mathrm{~b}$ & 10 & 52.63 & 06 & 37.50 \\
\hline $3 c$ & 11 & 57.89 & 08 & 50.00 \\
\hline $4 a$ & 18 & 94.73 & 15 & 93.75 \\
\hline $4 \mathrm{~b}$ & 10 & 52.63 & 17 & 106.25 \\
\hline $4 c$ & 11 & 57.89 & 04 & 25.00 \\
\hline $5 a$ & 14 & 73.68 & 09 & 56.25 \\
\hline $5 b$ & 11 & 57.89 & 09 & 56.25 \\
\hline $5 c$ & 12 & 63.15 & 12 & 75.00 \\
\hline $6 a$ & 09 & 47.36 & 07 & 43.75 \\
\hline $6 b$ & 12 & 63.15 & 13 & 81.25 \\
\hline $6 c$ & 10 & 52.63 & 08 & 50.00 \\
\hline $7 a$ & 10 & 52.63 & 04 & 25.00 \\
\hline $7 \mathrm{~b}$ & 12 & 63.15 & 06 & 37.50 \\
\hline $7 \mathrm{c}$ & 07 & 36.84 & 04 & 37.50 \\
\hline $8 a$ & 13 & 68.42 & 17 & 106.25 \\
\hline $8 b$ & 06 & 31.57 & 10 & 62.50 \\
\hline $8 c$ & 09 & 47.36 & 16 & 100.00 \\
\hline Std(fluconazole) & 19 & 100.00 & 16 & 100.00 \\
\hline
\end{tabular}

Graph 2 Comparison of the in vitro antifungal activity exhibited by the test compounds and standard drugs fluconazole

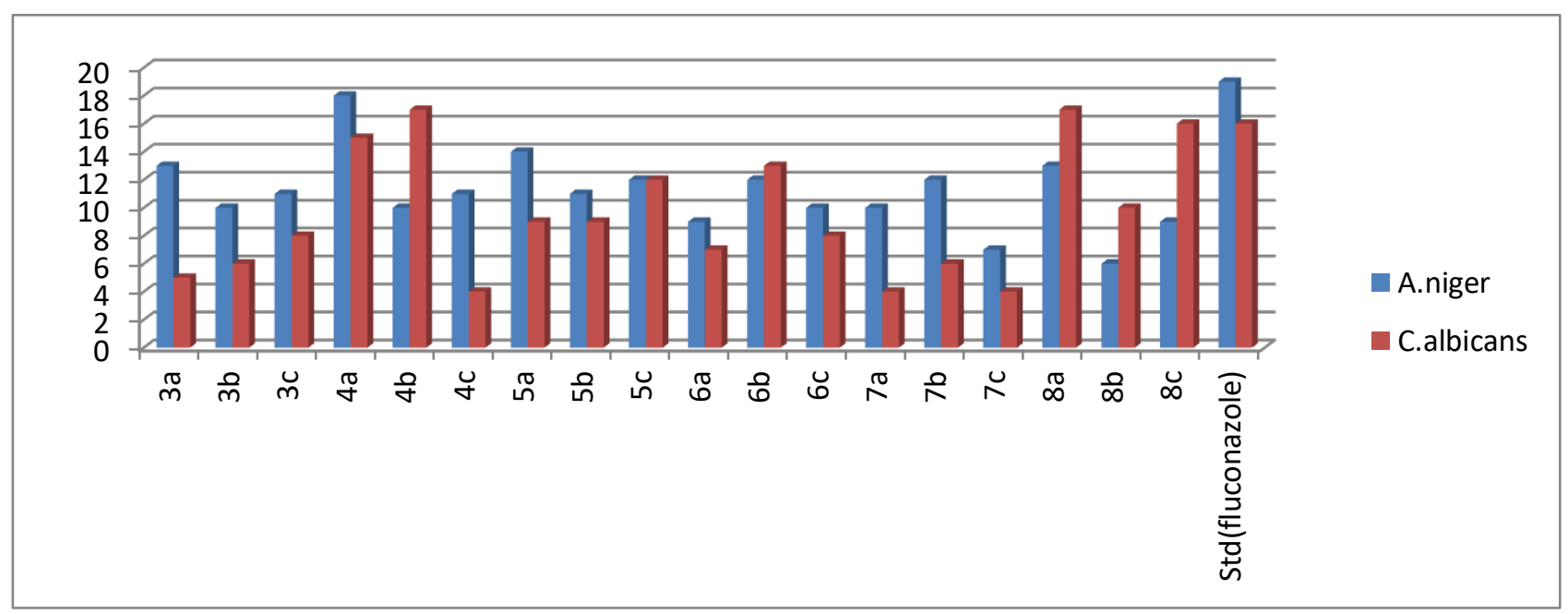


Anti-inflammatory activity

Table 5 effect of test and standard compound on carrageenan-induced oedema

\begin{tabular}{|l|l|l|l|l|l|}
\hline \multirow{2}{*}{ Comp. } & \multirow{2}{*}{ Dose (mg/kg,p.o) } & \multicolumn{4}{l|}{ Increase in paw volume (Mean \pm SEM)in ml at } \\
\cline { 3 - 6 } & & $0.0 \mathrm{~h}$ & $0.5 \mathrm{~h}$ & $1.0 \mathrm{~h}$ & $2.0 \mathrm{~h}$ \\
\hline Control(N/saline) & $2.5 / \mathrm{kg}$ & 0.0 & $0.83 \pm 0.13$ & $1.25 \pm 0.13$ & $1.73 \pm 0.13$ \\
\hline 3a & $50 \mathrm{mg} / \mathrm{kg}$ & 0.0 & $0.06 \pm 0.13^{* *}$ & $0.36 \pm 0.13^{* *}$ & $0.16 \pm 0.13^{* *}$ \\
\hline 3c & $50 \mathrm{mg} / \mathrm{kg}$ & 0.0 & $0.65 \pm 0.13^{*}$ & $0.16 \pm 0.13^{* *}$ & $0.13 \pm 0.13^{* *}$ \\
\hline 4b & $50 \mathrm{mg} / \mathrm{kg}$ & 0.0 & $0.46 \pm 0.14^{* *}$ & $0.28 \pm 0.14^{* *}$ & $0.13 \pm 0.13^{* *}$ \\
\hline $5 \mathrm{c}$ & $50 \mathrm{mg} / \mathrm{kg}$ & 0.0 & $1.46 \pm 0.14$ & $1.25 \pm 0.14$ & $1.48 \pm 0.14$ \\
\hline $6 \mathrm{a}$ & $50 \mathrm{mg} / \mathrm{kg}$ & 0.0 & $1.46 \pm 0.14$ & $1.95 \pm 0.13$ & $1.16 \pm 0.13$ \\
\hline 6c & $50 \mathrm{mg} / \mathrm{kg}$ & 0.0 & $1.63 \pm 0.13$ & $0.43 \pm 0.13$ & $0.11 \pm 0.13$ \\
\hline $7 \mathrm{~b}$ & $50 \mathrm{mg} / \mathrm{kg}$ & 0.0 & $0.4 \pm 0.13^{* *}$ & $0.11 \pm 0.13^{* *}$ & $0.0 \pm 0.13^{* *}$ \\
\hline $8 \mathrm{a}$ & $50 \mathrm{mg} / \mathrm{kg}$ & 0.0 & $1.5 \pm 0.13$ & $1.23 \pm 0.14$ & $0.6 \pm 0.13$ \\
\hline $8 \mathrm{c}$ & $50 \mathrm{mg} / \mathrm{kg}$ & 0.0 & $0.18 \pm 0.14^{* *}$ & $0.51 \pm 0.13^{* *}$ & $0.28 \pm 0.13^{*}$ \\
\hline Std.(diclofenac) & $50 \mathrm{mg} / \mathrm{kg}$ & 0.0 & $0.4 \pm 14^{* *}$ & $0.2 \pm 0.13^{* *}$ & $0.51 \pm 0.14^{* *}$ \\
\hline
\end{tabular}

The statistical significance of differences assessed with an analysis of variance (ANOVA), followed by Bonferroni $\mathrm{t}$-test test.Results are expressed in mean +_SEM. ( $N=6)$ significance levels ${ }^{*} \mathrm{P}<0.05$ and ${ }^{* *} \mathrm{P}<0.01$, compared with control respectively.

Graph 3 comparison results are expressed in mean \pm SEM for statistical significance of differences of above compounds.

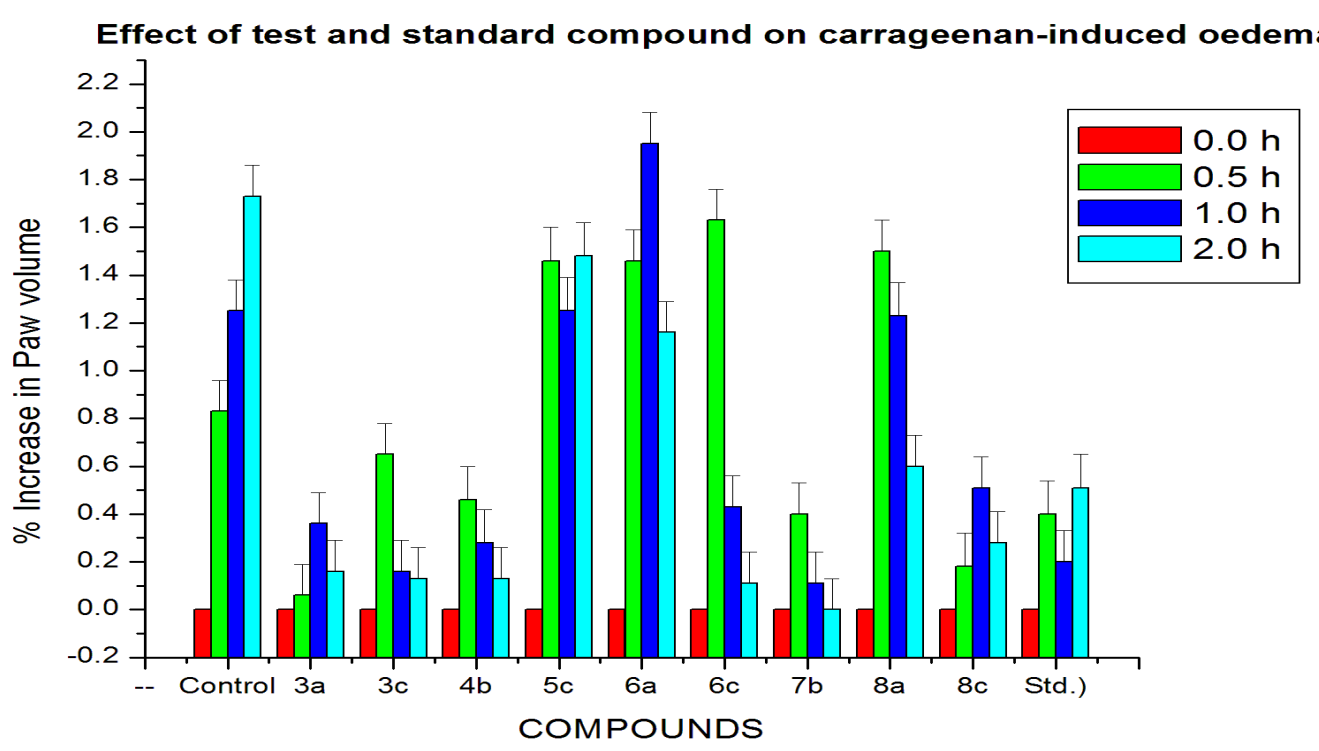

\section{RESULT AND DISCUSSION}

\section{Antimicrobial activity.}

Derivatives of 1-methyl-4(5-(4-(phenyl amino) phenyl)-1, 3,4-thiadiazol-2-e thiosemicar bazide (2a-f)were reacted with corresponding reactant dimity lamina, morph line and piper dine $(a-c)$ in the presence of formaldehyde and concentrated acid. All synthesized compounds were obtained in the range of 57.41-66.7\%yield. Purity and homogeneity of the synthesized compound were routinely checked by sharp melting point and TLC. Melting point of the all synthesized compound was observes between at 240.0$251.0^{-0} \mathrm{C}$.

$57.41-66,7 \%$ yield purity and homogeneity of the synthesized compound were routinely checked by sharp melting point and TLC .melting point of the all synthesized compounds was observed 240.0 t $251.0^{-0} \mathrm{C}$.

The in vitro antimicrobial activity of the synthesized compound was evaluated by cup plate method for bacteria viz. S. aurreus, $B$ subtilis , E. coli, $K$. pneumonia and fungi $c$. albecans , A Niger some compounds exhibited potent pharmacological activities as compared to the standard drugs.
The compounds $3 \mathrm{~b}$ and $4 \mathrm{a}$ exhibited highest activity i.e. each with $82.60 \%$ inhibition against $S$. aureous while the compound 4b, 5b, 6b, 7c showed 65.21, 69.56, 52.17 and $52.17 \%$ inhibition respectively against $S$. aureus. Against $B$. subtiles the compound $3 \mathrm{a}, 3 \mathrm{~b}$, and $4 \mathrm{c}$ showed $85.71,95.23$, $66.66 \%$ inhibition respectively and were the highest activity compound. While the compound for $4 \mathrm{a}, 5 \mathrm{a}, 6 \mathrm{c}, 8 \mathrm{~b}$ (each with $57.41 \%$ inhibition ) and $5 b$ (47.61\% inhibition )showed activity.

When tested against E.coli the compound 3c, 4a, 6b, 7a and 7c exhibited $60.86,52.17,52.17,52.17$ and $60.86 \%$ inhibition respectively and these compound showed Good activity among the tested compound. The highest activity was observed with 8c (with 69.56\% inhibition).

Against $K$. pneumoniae the compound $3 \mathrm{~b}$ (65.21\%),4c(60.86\% inhibition), 5a (60.86\% inhibition), 7a (65,21\% inhibition), $7 \mathrm{~b}$ (65.21\% inhibition) and 7c (65.21\% inhibition) exhibited good activity. Among the highest ac tested compounds 3a(69.56\%)showed activity.

All the synthesized compound were screened in vitro against the pathogenic fungal strains A.niger and c.albicans. The compound 3a (68.42\% inhibition), 5a (73.68\% inhibition), $5 c$ (63.15 inhibition), 6b, 7b (each with $63.15 \%$ inhibition) and $8 \mathrm{a}$ (68.42\% inhibition) showed excellent activities. 
The anti-inflammatory activity of the selected compound 3a ,3c, 4b, 5c ,6a, 6c, 7b, 8a and 8c was screened by carrageen induced rat paw oedema method against the standard drug diclofenac sodium. The activity was evaluated over a time frame of $2 \mathrm{~h}$, after the carrageen challenge, at intervals of 0.5 h., $1.0 \mathrm{~h}$. and $2.00 .5 \mathrm{~h}$.

After $0.5 \mathrm{~h}$, the compound $3 \mathrm{a}, 7 \mathrm{~b}$ and $8 \mathrm{c}$ showed $92.77,51.80$ and $78.31 \%$ oedema inhibition as compared to $51.80 \%$ oedema inhibition shown by the standard drug diclofenac sodium. the data indicate the short onset of action and comparable activity of these compound.

The standard drug declofenac sodium showed the maximum anti-inflammatory activity $(84.00 \%$ oedema inhibition). comparable activity at this time interval was exhibited by the compound 3a (71.2\% oedema inhibition), 3c (87.2\% oedema inhibition), $4 \mathrm{~b}$ (77.6\% oedema inhibition) and $7 \mathrm{~b}$ (91.2\% oedema inhibition).

At $2.0 \mathrm{~h}$ time interval $3 \mathrm{a}, 3 \mathrm{c}, 4 \mathrm{~b}, 6 \mathrm{c}, 7 \mathrm{~b}$, and $8 \mathrm{c}$ exhibited $90.75,92.48,92.48,93.64,100$ and $83.81 \%$ oedema inhibition respectively in comparison to $70.52 \%$ oedema inhibition shown by the standard drug. in brief compound $3 \mathrm{a}$ and $7 \mathrm{~b}$ showed excellent anti-inflammatory activity at time interval of $0.5,1.0$ and $2.0 \mathrm{~h}$.

\section{Statistical Analysis}

Table 5 result are expressed as mean \pm standard error of mean (SEM) of at least 6 animals per group. Statistical significance of differences between group was determined by one-way analysis of variance (ANOVA) followed by bonfeeroni t-test. For the statistical determination, statistical computerized software SIGMASTAT was used.

Statistical analysis was assessed for the test compound $3 \mathrm{a}$, $3 c, 4 b, 6 a, 7 b, 8 a$ \& 8c compare with control respectively. In pharmacological study anti-inflammatory effect of synthesized compounds were observed and found to be statically significant at the levels ${ }^{*} \mathrm{P}<0.05$ and ${ }^{* *} \mathrm{P}<0.01$ compared with control normal saline treated animals' group. Probability value less than $0.01(\mathrm{P}<0.01)$ was significant.

Test compound $3 \mathrm{a}, 3 \mathrm{c}, 4 \mathrm{~b}, 7 \mathrm{~b}$ and $8 \mathrm{c}$ showed significant decrease in oedema on rat's paw compared with the test compound 5c, 6a, 6c and $8 \mathrm{a}$ at significance level. The $\mathrm{F}_{\mathrm{cal}}$ (6.98933) $>\mathrm{F}_{\operatorname{tab}}$ (4.8317) hence there is a statistically significant difference $(\mathrm{P}<0.01)$ in the mean values of the treated groups .The test compound $3 a, 3 c, 4 b, 7 b a n d 8 c$ found as significant compound .However, the profile of compound was at the expected level.

\section{SUMMARY AND CONCLUSION}

In summary, designed and synthesized a series of N-Mannich bases of heterocyclic 1,3,4-thiadiazole 3-8(a-c) and characterization of the synthesized compound was carried was carried out by determining their melting points, $\mathrm{R}_{\mathrm{f}}$ value ,UV,IR, Spectra, 1H-NMR and evaluated for in-vitro antimicrobial and ant-inflammatory activities .The compound $3 \mathrm{~b}$ and 4 a showed highest activities against $S$. aureus while the compound $3 \mathrm{a}$ and $3 \mathrm{~b}$ were highly active against B.subtilis. It revealed that compound $3 \mathrm{~b}$ exhibited excellent activity against both bacteria. The compounds 3c, 7c and 8c showed very comparable activity as compare to the standard drug ciprofloxacin against the pathogen E.coli. It can be assumed that pipiridine ring is necessary in mannich base for antibacterial activity against Gram-negative E.coli.

The compound 3a was observed as the most active against $K$. pneumoniae. The in vitro antifungal activity of the synthesized compounds was also evaluated by cup-plate method.The study revealed that the compounds $3 a, 4 a, 5 a$ and $8 \mathrm{a}$ are the most active against the fungi A.niger .Attribution of structure dimethylamine group is necessary in Mannich base compounds for antifungal activity against A.niger. When compard with the standard drug Fluconazole, the compounds $4 a, 4 b, 5 c, 6 b, 8 a$ and $8 c$ showed excellent activity against the fungi C.albicans.

The anti-inflammatory activity of the randomly selected compounds was evaluated, on albino rats, by carrageen induced rat paw oedema method using the standard drug diclofenac sodium. The study was carried out over a frame of $2 \mathrm{~h}$ at intervals of $0.5,1.0$ and $2.0 \mathrm{~h}$. Fluconazole, the compounds $3 \mathrm{a}, 4 \mathrm{~b}, 7 \mathrm{~b}$ and $8 \mathrm{c}$ possess more potent antiinflammatory activity compared with the standard drug.

To summarize the overall performance, the compound $7 \mathrm{~b}$ exhibited excellent anti-inflammatory pharmacological activity. Structurally the compound $7 \mathrm{~b}$ has a greater number of unsaturated hydrocarbons in Schiff base which shows good lipophilic properties with electron rich morpholine ring in Mannich base.

\section{REFERENCES}

1. Dhapalapur M. G., Sabnis, S.S.,Deliwala C.V., J. Med. Chem., 1968; 11,pp-1014.

2. Patole J., Shingnapurkar D., Padhye S., Ratledge C., Bioorg. Med. Chem. Lett., 2006;16, pp-1514.

3. Turner S., Myers M., Gadie B., Nelson A. J., Pape R., Saville J. F., Doxey J. C., Berridge T. L., J. Med. Chem., 1988; 31, pp-902.

4. Turner S., Myers M., Gadie B., Hale S. A., Horsley A., Nelson A. J., Pape R., Saville J. F., Doxey J. C., Berridge T. L., J. Med. Chem., 1988; 31, pp-907.

5. Kurtzer F., Katritzky A. R., Boulton A. J., Advances in Heterocyclic Chemistry, Academic Press, New York; 1965, 5, pp-165-209.

6. Morrison R. T. and Boyd R. N., "Organic Chemistry", 6th Edn., Pearson Education, Inc., 2005, pp-715.

7. Agarwal O. P., "Organic Chemistry, Reaction and Reagents", 41 ${ }^{\text {th }}$ Edn. Goel Publishing House, Meerut (UP), 2006

8. Adam R., "Organic reaction", John willey and Sons, New York, 1996, 1, pp-403.

9. Pandeya S. N., Sriram D., Nath G., DeClercq E., "Synthesis, antibacterial, antifungal and anti-HIV activities of norfloxacin Mannich bases", Eur. J. Med. Chem.;1999, 9, pp-25-31.

10. Yogeeswari P., Thirumurugan R., Kavya R., Samual J. S., Stables J., and Sriram D., "Synthesis, antibacterial, antifungal and antiHIV evaluation of schiff and Mannich bases of isatin derivatives with 3-amino-2-methylmercapto quinazolin-4-3Hone", Eur. J. Med. Chem.;2004, 39, pp-729-734.

11. Pandeya S. N., Sriram D., Nath G., DeClercq E., Eur. J. Med. Chem; 1999, 9, pp-25-31.

12. Pelczar J. M. et al, Microbilogy $5^{\text {th }}$ Edn. Tata McGraw Hill Publisher, 2003, pp-504.

13. Ananthanaryan R., Paniker C.K.J., Textbook of Microbiology, $7^{\text {th }}$ Edn., Orient Longman, 2005, pp-99.

14. Kulkarni S.K., "Hand book of Experimental Pharmacology", 3 rd Edn. Publisher Vallabh Prakashan, 1999, pp-121.

15. Winter C.A., et al., Proc. Soc. Exp. Biol., 1962, 111, pp-544. 